\title{
AUNQUE DIOS NO EXISTIERA. LA CRISIS DE LA SECULARIZACIÓN
}

\author{
EVEN IF GOD DID NOT EXIST. THE CRISIS OF SECULARIZATION
}

\author{
Isabel Roldán Gómez ${ }^{1}$ \\ Universidad de Salamanca (España)
}

Recibido: 05/08/2015

Aceptado: 10/01/2016

\begin{abstract}
Resumen: En este artículo planteo algunas claves acerca de cuál debe ser el lugar de la religión en la esfera público-social. Para ello, analizo brevemente el concepto de secularización del que son beneficiarias las sociedades occidentales. En segundo lugar, examino el lugar de la religión en la esfera pública a partir de la propuesta de Jürgen Habermas, dividiéndola en dos niveles: un nivel normativo, de interacción con lo religioso, que se apoya a su vez en un nivel descriptivo, de análisis de la religión en conexión dialéctica con la razón secular. Por último, extraigo algunas conclusiones relativas al éthos cívico que se espera de los agentes sociales.
\end{abstract}

Palabras clave: religión; secularización; postsecularismo; iglesia; Habermas.

\begin{abstract}
In this paper I analyze some keys on what should be the place of religion in public-social sphere. First, I briefly discuss the concept of secularization that are beneficiaries of Western societies. Second, I examine the place of religion in the public sphere from the proposal of Jürgen Habermas, dividing it into two levels: a policy level of interaction with religion, which is based in turn on a descriptive level, of analysis of religion in dialectical connection with secular reason. Finally, I draw some conclusions concerning the civic ethos which is expected of the stakeholders.
\end{abstract}

Key words: religion; secularization; postsecularism; church; Habermas.

[1] (iroldangomez@usal.es) Isabel Roldán Gómez. Profesora de Filosofía. Contratada predoctoral. Su trabajo de investigación en la Universidad de Salamanca está financiado por un contrato predoctoral (Orden EDU/1083/2013 de 27 de diciembre. Junta de Castilla y León). 


\section{Introducción}

El 7 de enero de 2015 dos hombres armados con rifles de asalto entraron en las oficinas del semanario Charlie Hebdo en París y asesinaron a once de sus trabajadores al grito de "Alá es grande». Dos días más tarde, también en la capital, un ciudadano francés de origen musulmán acabó con la vida de una policía y posteriormente se atrincheró en un supermercado judío, donde asesinó a otras cuatro personas. La causa de estos atentados (si es que es legítimo establecer una relación causal en la barbarie) fue la caricaturización de Mahoma, símbolo sagrado del Islam y cuya representación supone una profunda ofensa para la comunidad musulmana, en la revista Charlie Hebdo.

El atentado fue condenado por, prácticamente, toda la comunidad internacional (portavoces religiosos, presidentes de gobierno y ciudadanos) y el símbolo de repulsa hacia esos crímenes fue la marcha conjunta de los líderes políticos por las calles de París el 11 de enero de 2015. «Je suis Charlie» se convirtió en el lema para la defensa de la libertad de expresión; una libertad reconocida normativamente en la Declaración Universal de los Derechos Humanos de 1948 (art. 19) y en el Pacto Internacional de Derechos Civiles y Políticos de 1966 (art. 19). Sin embargo, esta libertad no es ilimitada, a tenor de lo que sostiene, también, el artículo 20 del mencionado Pacto ${ }^{2}$. ¿Dónde colocar, entonces, el límite preciso entre libertad de expresión y apología? Y, por extensión, ¿se debe autolimitar la libertad de expresión por respetar una cosmovisión, en este caso el Islam, cuyos símbolos son vanos para nuestra cultura?

Estos interrogantes vienen a ratificar que los sucesos de París no son un hecho aislado. Son la punta del iceberg de una problemática mucho más profunda que tiene, además, amplia resonancia en la teoría política contemporánea (Rawls, Habermas y Taylor, entre otros, se han ocupado de ella) y que puede reformularse del siguiente modo: ¿cuáles deben ser los límites entre religión y secularización en la esfera público social?

\section{Evolución y límites de la secularización}

En el siglo XVII, Hugo Grocio, jurista holandés, acuñó la expresión etsi Deus non daretur para fundamentar el derecho natural a partir de la premisa humana, es decir: aunque Dios no existiera; sólo con los recursos

[2] «Toda apología del odio nacional, racial o religioso que constituya incitación a la discriminación, la hostilidad o la violencia estará prohibida por la ley», art. 20 del Pacto Internacional de Derechos Civiles y Políticos de 1966, consultado en http://www.boe.es/boe/dias/1977/04/30/ pdfs/A09337-09343.pdf (última consulta el 03.03.2015)

Thémata. Revista de Filosofía №53 (2016) pp.: 311-326. 
que la razón aporta. Ello significó colocar el acento en el derecho natural (el hombre como hombre) y no en el derecho sobrenatural (el hombre como criatura de Dios).

Valga este ejemplo para ilustrar cómo el derecho se fue emancipando de la esfera religiosa, fundamentando sus contenidos a partir de las premisas de la razón natural. Pero no fue el derecho la única disciplina que se configuró autónomamente en la Historia europea ${ }^{3}$. También se fueron forjando, si bien a distintos ritmos, los siguientes marcos: 1.Un espacio del pensamiento independiente de la religión -la razón natural, la ciencia-; 2. Un poder político a partir de las leyes humanas -la separación Iglesia/Estado-; 3. Un modus vivendi hecho a la medida mortal -la ética autónoma-. Ciencia, política y ética se erigieron así en pilares del Estado secular. Éste viene definido por el proceso de diferenciación entre religión (organizada en iglesia) y esferas institucionales seculares (que asumen funciones antes reservadas a la Iglesia). Cuando este proceso adquiere una tendencia sis-témica y se implementa en todos los subsistemas sociales, recibe el nombre de secularización ${ }^{4}$, si bien este concepto se puede interpretar desde distin-tos marcos.

Pues bien, desde la sociología de la religión, encarnada fundamentalmente en Comte y Weber, se asumió este proceso secularizador de un modo teleológico, como si se tratara de un nuevo paso del mito al logos en el que, al final del proceso, se disolvería completamente la religión. Los seres humanos se irían quedando solos ante sí mismos y habrían de servirse de sus propios recursos. Así, «con la secularización se registra el volverse invisible la mano de Dios y el le monde va de lui-même ${ }^{5}$ (Luhmann, 2007, p. 247).

El pronóstico, desde luego, no era muy alentador para el futuro de la religión: las esferas especializadas institucionalmente, progresivamente, expulsarían de su seno la fundamentación religiosa y se organizarían autónomamente por medio de criterios instrumentales. Todo ello a la luz de lo que se venía sucediendo en la Europa del s. XIX (Revolución Industrial, afirmación nacional, movimientos políticos y sociales, reflexión acerca de la Ilustración).

En el ámbito teórico, la tesis de la secularización fue dada por sentada no sólo entre los sociólogos, sino también en las primeras filas de la antro-

[3] Me centro en el análisis de Europa Occidental, partiendo de la premisa de algunos sociólogos según la cual lo que se considera secularización se habría desarrollado exclusivamente en Europa Occidental. Véase: Berger, P. y Luckmann, T. (1997), Modernidad, pluralismo y crisis de sentido. La orientación del hombre moderno, Paidós, Barcelona, pp. 70-77)

[4] Para una ampliación del término «secular», véase: Casanova, J. (2000), Religiones públicas en el mundo moderno, PPC, Madrid, pp. 26-33; también: Luhmann, N. (2007), La religión de la sociedad, Trotta, Madrid, p. 241 y ss.

[5] El mundo marcha por sí solo.

Thémata. Revista de Filosofía No53 (2016) pp.: 311-326. 
pología y la filosofía (Marx, Tylor, Frazer, Simmel, Freud, por poner algunos ejemplos). Todos ellos coincidieron, grosso modo, en que la religión tuvo un origen histórico, época en la que cumplía con determinadas funciones (mágicas, integradoras, interpretativas, políticas o ideológicas.) pero, una vez que esas funciones fuesen asumidas por otras esferas, la religión desaparecería. Era tal el consenso respecto de la validez de la teoría de la secularización, que ni siquiera parecía necesario examinarla con rigor y observar las premisas empíricas de las que arrancaba (Casanova, 2000, p. 33).

A partir de los años 60 del s. XX, sin embargo, el mismo concepto de secularización comenzó a resultar poco operativo en sociología, pues no describía una realidad en la que la religión se hubiera retirado del todo de la esfera pública, ni hubiese desaparecido, pese a la pérdida de funciones institucionales (por ejemplo, en los ámbitos político o educativo6 ${ }^{6}$. Así, una nueva interpretación postuló que la religión no estaba desapareciendo, sino que se estaba invisibilizando, pero creciendo sobre bases sociales -la familia, el ámbito privado, algunas comunidades-distintas a las del Estado (Luckmann, 2000, p. 114).

Desde los años 90 del siglo pasado hasta la actualidad, el análisis de la religión recorre distintas direcciones. Por un lado, se señala, en contra del análisis de Luckmann, que la privatización de la religión no es una tendencia sistémica sino sólo una opción en los procesos de individuación religiosos (Casanova, 2000, p. 62). Por otro lado, ya el hecho de establecer una tensión entre dos polos -religión/secularización- significa asumir un parámetro predefinido ideológicamente, como si la realidad fuera binaria (Douglas, 1978, p. 161), cuando lo cierto es que no lo es. Por su parte, algunas voces de la teoría feminista (Elshtain, 1981) sostienen que la división privado/público, heredada como se sabe de la tradición liberal, no resulta adecuada para enfrentarnos a determinadas problemáticas, entre ellas, la perspectiva de género, la relación con la naturaleza, etc. Y parece que tampoco la religión, que impregna de forma indiferenciada toda dimensión personal y social, se dejaría reducir a este esquema binario: ya «el término privado resulta una descripción poco afortunada para la religión porque su contraconcepto, público, se aplica de hecho a la mayoría de las prácticas religiosas» (Luhmann, 2007, p. 251).

Todos estos ejemplos aportados habrían de ser sometidos a un análisis mucho más detallado de lo que aquí es posible. Lo que sí parece evidente es que la religión ostenta una dimensión pública, aún hoy, y dicha dimensión contradice los pronósticos de la teoría de la secularización.

[6] No obstante, no es rotunda esa retirada de la religión de la esfera educativa. En el caso de España, al menos, la nueva legislación respecto de la asignatura de religión constituye el caballo de batalla de la relación Iglesia-Estado: Consultado en http://www.boe.es/boe/ dias/2015/02/24/pdfs/BOE-A-2015-1849.pdf (última consulta el 02.03.2015)

Thémata. Revista de Filosofía №53 (2016) pp.: 311-326. 
Algunas de las claves para comprender ese carácter público de la religión las ofrece la postura de Jürgen Habermas, postura que analizaré en el siguiente apartado.

\section{Prospectivas de la religión en la esfera público-social}

Cuál debe ser el lugar de la religión en la esfera pública social es una cuestión ampliamente discutida en el pensamiento político contemporáneo. La sentencia que origina la controversia corresponde a John Rawls y afirma que en la esfera pública sólo valdrían las razones públicas, atendiendo al deber cívico que los ciudadanos se deben unos a otros (Rawls, 1996, p. 252). Con «esfera pública» aquí se hace referencia no sólo al contexto formal de las instituciones, el parlamento, o la administración pública, sino también al ámbito informal: por ejemplo, medios de comunicación y discusiones políticas. Por «razones públicas» se entienden aquéllas que pueden ser comprendidas y asimiladas por todos los ciudadanos, a saber: creyentes de un credo, de otro, o no creyentes. Desde esta perspectiva, los argumentos religiosos tendrían que quedar al margen de la esfera pública en sentido amplio. Lo cual ha de leerse también del siguiente modo: la religión ha de permanecer estrictamente en el ámbito privado.

Esta exigencia rawlsiana para el correcto funcionamiento de la deliberación pública convocó a enérgicos críticos: tanto desde las propias filas liberales (Wolterstorff, Weithmann) como desde otras corrientes de la filosofía política: comunitarismo (Taylor) o republicanismo kantiano (Habermas). El punto de acuerdo de todos estos críticos es que tal requisito supone una delimitación excesivamente secularista de la política; requisito que además es prácticamente imposible de cumplir: por un lado, los ciudadanos religiosos tendrían que dividir sus razones constantemente entre públicas y privadas (Wolterstorff, 1997, p. 105), lo cual les llevaría a convertirse en la cabeza de Jano, adoptando un rostro para su vida personal, y otro para su vida política. O peor aún: la exigencia de una esfera pública despojada de argumentos religiosos conduciría a los creyentes a retrotraerse a su vida personal y a no participar en los asuntos públicos, o a desarrollar una vida política independiente. Tendríamos, con ello, sociedades paralelas (Kymlicka, 2002), cada una de ellas con sus propios códigos, normas y valores. Pero además, algunas críticas apuntan a que uno no puede elegir el estado cognitivo desde el cual juzgar el mundo (Reder, en Habermas, 2009, p. 135), es decir: aunque se quiera, el ciudadano creyente no puede "vestirse» de secular para entrar en la vida pública, pues

Thémata. Revista de Filosofía №53 (2016) pp.: 311-326. 
los argumentos religiosos y seculares están imbricados en su razón, con lo que la exigencia rawlsiana no tendría mucho sentido.

\subsection{La cruz compartida}

Ante esta disyuntiva -esfera pública ¿con o sin religión?-, Habermas plantea una posible medida. Este autor admite que, más allá del umbral institucional, efectivamente sólo han de valer las razones públicas, lo que se traduce por ejemplo en que las leyes promulgadas deben estar justificadas en un lenguaje accesible para todos. Ahora bien, esta separación institucional entre religión y política característica del Estado democrático no ha de convertirse en una carga mental y psicológica indebida para los ciudadanos creyentes (Habermas, 2006, p. 137).

En el escenario informal de la esfera pública, los creyentes tendrían derecho a expresar sus convicciones religiosas con absoluta libertad. Esto obedece a dos razones fundamentales. En primer lugar, como se ha señalado, el Estado no debería apartar del juego político a ningún grupo ciudadano: no sólo por el éthos cívico que se le presupone, sino porque, en segundo lugar, aún no hemos calibrado verdaderamente el potencial de sentido que esa comunidad religiosa podría aportar al Estado (me ocuparé de este punto en el siguiente apartado). Quiere decirse que las religiones podrían ofrecer contenidos de verdad (Habermas, 2006, p. 139) irrenunciables para la convivencia. Contenidos que, por supuesto, habrían de ser filtrados al espacio público mediante una traducción a lenguaje secular.

¿Quién se ocupa de esta traducción? En este punto, la postura conciliadora del filósofo alemán convoca a numerosos críticos. Y es que la solución que propone, para evitar que los creyentes carguen con todo el peso de la cruz (pues se supone que ya bastante tienen con reconocer el Estado secular), es que sean los propios ciudadanos laicos los que, en un ejercicio de solidaridad cívica, reconozcan el contenido potencial de verdad de los enunciados religiosos y lo trasladen a lenguaje secular (Habermas, 2006, p. 140).

Ahora bien, si se llevara este ejercicio a la práctica nos encontraríamos con situaciones de lo más variopintas. Pongamos por caso: un ciudadano ateo, defensor de una ley para permitir los matrimonios entre personas de un mismo sexo, tendría que estar abierto al posible contenido de verdad de los argumentos religiosos (Levítico, 18:22), que exhiben rotundamente lo ilícito de la homosexualidad. La incoherencia salta a la vista, pero hay más. Un creyente no puede elegir el estado cognitivo desde el cual juzgar el mundo, pues su cosmovisión es totalizadora, inunda todos los poros de su existencia. De igual modo, un ciudadano ateo tampoco puede poner en-

Thémata. Revista de Filosofía №53 (2016) pp.: 311-326. 
tre paréntesis su ateísmo para, en un ejercicio de civismo, admitir que el dogma contra el que se revela quizá encierre alguna verdad. Estaría, con ello, traicionando su cosmovisión: su ateísmo en este caso y, siguiendo las mismas premisas del propio Habermas, estaría siendo deshonesto consigo mismo (Lafont, 2007). ¿No es ésta también una indebida carga para los ciudadanos laicos?

Otra cuestión sería la de la posibilidad de la traducción misma. Habermas admite que ciertos dogmas, que podrían interferir en el proceso de traslación a lenguaje secular, tendrían que ser dejados de lado, o ser considerados «accesorios históricos».

La hermenéutica racional debe dejar de lado muchos dogmas de fe a título de accesorios históricos, por ejemplo el dogma de la resurrección de la carne. También debe despojar de su significado especial a otros dogmas, como la encarnación de Dios en la persona de Jesucristo, o reinterpretar, por ejemplo, la gracia divina como un imperativo a actuar por nosotros mismos (Habermas, 2006, p. 222).

Sin embargo, habría que comprobar si los creyentes, también racionales, renunciarían a tales dogmas sin con ello desgajar su fe en, por un lado, lo que es susceptible de ser traducido y, por otro, lo que aparece en su fe como «mero accesorio histórico». ¿No sería esto también una carga indebida para los creyentes, no ya en su existencia pública sino incluso en la privada: tener que desentrañar qué es susceptible de ser traducido y qué no?

En suma, parecería que sólo a posteriori, sólo después de haber llevado a cabo la traducción, se revisten los enunciados religiosos de racionalidad. Pero, si esto es así, lo que se hace es diseccionar las religiones y seleccionar los contenidos aptos para la razón pública, o lo que es lo mismo, los que la razón pública re-conoce como aptos. Ésta es precisamente una de las críticas que dirige Flores d'Arcais a Habermas en sus célebres Once tesis, a saber: que «el argumento religioso es válido si y solo si resulta superfluo» (d'Arcais, 2008).

Por último, cabría cuestionar hasta qué punto se puede establecer una separación entre esfera pública formal e informal. En Habermas, los argumentos religiosos sólo tendrían cabida en el contexto informal puesto que, a partir del umbral institucional, se impondría una estricta razón secularista, vinculante para el conjunto de la ciudadanía. Esto plantea dos cuestiones. La primera de ellas es que, así concebida, la esfera pública informal parecería un coladero en el que todo vale, frente a la depurada y racional esfera formal. Cuanto menos, esto contraría el requisito de que entre ambas esferas exista una vinculación. Es más, desde las teorías de 
la deliberación se insiste en que una democracia sana es aquélla cuyas instituciones se nutren del debate público, en la medida en que éste genera resultados y no mera cháchara.

Ésta es, de hecho, la segunda cuestión que se le ha criticado a Habermas, a saber: la rígida distinción que hace entre esfera pública formal e informal, o entre esfera política y esfera social. Si se deja espacio para los argumentos religiosos en el ámbito informal, ¿por qué detenernos ahí? Acudiendo a los mismos presupuestos de Habermas, ¿por qué no inundar también la esfera formal con argumentario religioso? De hecho, existen casos en los que el discurso religioso ha jugado un importantísimo papel en las luchas en la esfera política. Tenemos el ejemplo de Martin Luther King en Estados Unidos, que logró luchar contra prejuicios profundamente arraigados amparándose en un lenguaje religioso (Ungureanu, 2013).

Sin embargo, frente a todas estas críticas encaminadas a configurar un espacio público laico, se puede esgrimir un argumento: la secularización del Estado no es lo mismo que la secularización de la sociedad (Habermas, 2008). Ello parece indicar que lo político y lo social tienen distintas velocidades: mientras que las esferas institucionales del Estado se racionalizan (esto es: tienden a la autonomía funcional) y «expulsan» a lo religioso de su seno, en el ámbito público-social se revitaliza la religión: como forma comunitaria de sentido, como eje social de la cosmovisión subjetiva y, por último, como reivindicación política.

De hecho, como señalé al principio, las manifestaciones religiosas en el ámbito público no dejan de sucederse. Se puede alegar que el ejemplo indicado (el atentado de Charlie Hebdo) no es estrictamente una "manifestación religiosa" sino un acto de barbarie encubierto. En este caso la religión sería una excusa, un pretexto para el crimen. Ésta no es, desde luego, una puntualización desdeñable. Pero lo que quiero resaltar en este artículo no es el uso (legítimo o no) que pueda hacerse de los contenidos religiosos, sino la tensión no resuelta entre religión y secularización; tensión que obedece a las distintas velocidades de la "secularización» y que tiene como subproducto hechos como los de París.

¿Cómo encarar, entonces, la presencia de la religión desde una perspectiva secularizada, esto es, asumiendo una estricta separación entre Iglesia y Estado, la autonomía de la moral, y la independencia de las ciencias institucionalizadas? ¿Realmente puede entrar la religión -que, recordemos, también es una esfera institucionalizada- en lo público y seguir manteniendo esos tres requisitos del Estado secular? ¿Aceptará la religión, manteniéndose fiel a su corpus doctrinal, la total autonomía del individuo por encima de toda instancia sagrada?

En estos interrogantes, y no en los polos absolutos del conflicto, reside a mi juicio la tensión referida entre religión y secularización. La 
religión, en tanto que esfera institucional, aspira a empoderarse públicamente, asumir funciones de control. Y no existiría ningún problema si los parámetros de ese empoderamiento (jerarquía institucional, dogmas de fe, evolución interna de la Iglesia, ausencia de deliberación) no fuesen, por definición ${ }^{7}$, incuestionables.

Si lo público es polifónico, toda religión que se presuma única (y esto vale para las llamadas "religiones de libro») debe estar dispuesta, al menos, a reconocer las notas disonantes de otros credos y a seguir el ritmo que marca el Estado secular como director de orquesta.

\subsection{Postsecularismo: la conciencia de lo que falta}

Como señalé al inicio, el pensamiento de Jürgen Habermas puede articularse en dos niveles, de tal modo que quede planteado no sólo cuál debe ser el lugar de la religión en la esfera pública sino, de facto, cuál es, qué espacio ocupa, qué funciones asume. A propósito de ello, Habermas relata, en el artículo denominado «La conciencia de lo que falta» lo siguiente:

El 9 de abril de 1991 se celebró en la colegiata de San Pedro de Zúrich una ceremonia fúnebre en memoria de Max Frisch. Al empezar, Karin Pilliod, su compañera sentimental, leyó ante los presentes una breve nota del fallecido, en la que se decía, entre otras cosas: «Damos la palabra a los allegados, sin amén. Agradezco a los párrocos de San Pedro de Zúrich que hayan permitido que el ataúd se encuentre dentro de la iglesia durante nuestro funeral» [...].No hubo sacerdote ni bendición [...]. La ceremonia no me pareció particularmente rara; pero sí el lugar y la forma en que se desarrolló [...]. Con la elección de aquel lugar [Max Frisch] dejó público testimonio de que la modernidad ilustrada carece de un lugar adecuado equivalente al espacio religioso donde se celebra el último rîte de passage, que pone el broche final a toda una vida. Podemos entender su gesto como la expresión de la melancolía por la pérdida de algo irreparable. Pero también podemos entenderlo como un acontecimiento paradójico que nos dice algo sobre la razón secular (Habermas, 2009, p. 53 y ss.).

A este sentimiento de pérdida se refiere el concepto de "postsecular», término acuñado por Habermas para describir la situación social y moral de las sociedades europeas. Se trata de un término adecuado, por lo que tiene de amplio, para describir una realidad política y social controvertida, aunque se torna resbaladizo, también por su amplitud, desde una perspectiva filosófica. A partir de ella, Habermas pretende hacer hincapié en la relación que ha mantenido el proyecto ilustrado con su propia heren-

[7] Me refiero a la definición interna que hacen de sí las propias religiones.

Thémata. Revista de Filosofía $\mathrm{N}^{\circ} 53$ (2016) pp.: 311-326. 
cia judeocristiana ${ }^{8}$. La secularización, entendida como proceso unidireccional que encarna un nuevo paso del mito al logos, no es capaz de reabsorber cierta dimensión humana que sí reconocía la religión (sentido comunitario, capacidad de trascendencia, solidaridad no estratégica...).

Por consiguiente, dando un paso más, lo postsecular apuntaría a ese estado de las sociedades modernas en el que el proceso secularizador no basta para responder a las necesidades políticas, sociales y espirituales de los ciudadanos. Quiere decirse que, en el lapso de tiempo que media entre la época de incuestionable autoridad religiosa y la posterior emancipación de los dogmas (emancipación expresada mediante la separación entre Iglesia y Estado), algo se nos perdió por el camino. Exactamente qué, nadie lo sabe; pero lo cierto es que el neutralismo inherente a lo que denominamos «secular» no parece ya servir. No hablo sólo de la pérdida de una cosmovisión que dote de sentido nuestra existencia particular. Resulta más grave aún: de la secularización ya ni siquiera podemos aprovechar el terreno neutral del que emergían nuestros argumentos, como señala la expresión de "esfera pública polifónica» (Cortina, 2011). Ello se traduce en que modernidad no es sinónimo de neutral, sino de plural: el problema del sentido, entonces, no sería el del vacío que haya dejado la religión en la constitución de la razón secular, como parece apuntar Habermas; sino, por el contrario, una infinidad de sentidos compitiendo según las leyes del mercado. Así, «el factor más importante en la generación de crisis de sentido en la sociedad y en la vida de los individuos tal vez no sea el secularismo supuestamente moderno, sino el pluralismo moderno» (Berger \& Luckmann, 1997, p. 74).

En cualquier caso, desde estas interpretaciones, parece que vivir "como si Dios no existiera" nos haya convertido en seres desorientados, tanto individual como socialmente. El postsecularismo, por ende, ya no sólo es un hecho, sino que se trata también de una necesidad: necesidad, fundamentalmente, de pararse y reflexionar sobre la genealogía de nuestra razón. No se trata de volver acríticamente a lo religioso e integrar nuestra existencia en el seno de una iglesia. La exigencia, al menos desde el mirador agnóstico (o escéptico) de la filosofía, debe encaminarse a la comprensión del proyecto frustrado de la modernidad, que aparece encarnado en la asunción de los tres estados comtianos (teológico-metafísico-positivo), y cuya realización final nos liberaría finalmente de lo religioso.

El análisis de Max Weber (Weber, 2004) sobre la razón instrumental, y posteriormente el de Adorno y Horkheimer en la Dialéctica de la Ilustración (Adorno \& Horkheimer, 2009), orbitan también alrededor de la

[8] Véase: Habermas, J. (1994), «¿Israel o Atenas? A quién pertenece la razón anamnética. Sobre la unidad en la diversidad multicultural», Isegoría, 10, pp. 107-116

Thémata. Revista de Filosofía №53 (2016) pp.: 311-326. 
problemática acerca de la constitución de la razón secular: ¿qué podemos esperar de una razón que sólo parece servirnos para calcular estratégicamente la consecución de fines? Y, por extensión, ¿podríamos cultivar una razón no religiosa que no obstante transcienda lo puramente instrumental?

\section{Consideraciones finales}

Las constantes incursiones ${ }^{9}$ de la religión en el ámbito, no ya social, sino político y parlamentario, han suscitado, con razón, una reacción atea que plantea la expulsión de la religión de todo ámbito público a partir de una única y rotunda premisa: Dios no existe, por lo tanto, la alucinación de su existencia debe vivirse en privado. Desde esta perspectiva cabe entender, por ejemplo, el ateísmo activo del filósofo Richard Dawkins, plasmado en la campaña de "autobuses ateos» en Inglaterra ${ }^{10} \mathrm{o}$ en algunas de sus obras divulgativas (Dawkins, 2006).

A la luz de dichas incursiones, resulta lícita la defensa del Estado secular: plasmado en la estricta separación entre Iglesia y Estado, en la conquista de derechos para las mujeres (derechos de los que, por cierto, no gozan en las instituciones eclesiásticas $\left.{ }^{11}\right)$, y en el reconocimiento de la ciencia institucionalizada. Ahora bien, convertir esta defensa política en una disputa teológica a partir del argumento-Dios (o el argumento noDios) resulta, a mi juicio, una empresa ilegítima y estéril; ilegítima porque se pasa de un plano metafísico (la existencia de Dios) a uno político (la religión en el ámbito público), fundiendo así religión e Iglesia en un mismo concepto, cuando lo cierto es que son cosas muy distintas (Luckmann, 1973 , pp. 32 y ss.); y estéril porque lo único que se consigue atacando a la raíz de las creencias (y no a las aspiraciones cesaropapistas de la Iglesia) es el cuestionamiento de una cosmovisión concreta, pero no reconocimientos políticos, ni por supuesto consenso social.

En definitiva, al plantear cuál es el lugar de la religión en la esfera pública informal, debería surgir inmediatamente la pregunta por el lugar

[9] Ejemplos en España: registros por parte de la Iglesia de propiedades públicas (http:// www.eldiario.es/andalucia/Cordoba-descubre-Iglesia-inmatriculo-publicas_0_311119043. html, última consulta el 16.03.2015), o la nueva ley de educación que incluye de manera obligatoria la asignatura de religión en todos los centros públicos del Estado (http://www.boe.es/ boe/dias/2015/02/24/pdfs/BOE-A-2015-1849.pdf, última consulta 16.03.2015).

[10] http://www.elmundo.es/elmundo/2008/10/23/ciencia/1224754600.html (última consulta el 03.03.2015)

[11] A este respecto, véase: PINTOS, M. \& TAMAYO ACOSTA, J.J., «Los cuerpos colonizados. Las religiones contra las mujeres» en Ecología y género en diálogo interdisciplinar, Alicia Puleo (ed.), Madrid: Plaza y Valdés, 2015

Thémata. Revista de Filosofía $\mathrm{N}^{\circ} 53$ (2016) pp.: 311-326. 
de los creyentes en el ámbito público social pues, al fin y al cabo, la problemática de la religión no sería tal si no estuviera encarnada en individuos concretos. Pero esta pregunta se torna un tanto absurda: obviamente, el lugar de los creyentes en el ámbito informal de lo público es exactamente el mismo que el de los no creyentes, en la medida en que lo público, por definición, es o debe ser una construcción conjunta; y ya está siendo, no es un bosquejo de algo que ha de ser.

Por ello, la secularización no puede asumirse desde una perspectiva teleológica, como algo a lo que el ser humano está abocado por naturaleza. Todas las interpretaciones de este tipo, de hecho, han llevado a una imposición por la fuerza de ese destino soñado. La secularización es un proceso que hay que construir, no batallar, y eso significa que, por paradójico que resulte, debe integrar dialécticamente a lo religioso en su reflexión: no el dogma, pero sí la historia; no las creencias, pero sí sus causas; no la institución, pero sí a los individuos. En suma: no basta con vivir como si Dios no existiera; hay que vivir con la responsabilidad que implica la ausencia de Dios.

\section{Referencias bibliográficas} Trotta, 2009

Adorno, T. \& Horkheimer, M., Dialéctica de la Ilustración, Madrid:

Audi, R. \& Wolterstorff, N., Religion in the Public Square. The Place of Religious Convictions in Political Debate, Lanham: Rowman \&Littlefield Publishers, 1997

Berger, P. \& Luckmann T., Modernidad, pluralismo y crisis de sentido. La orientación del hombre moderno, Barcelona: Paidós, 1997

Casanova, J., Religiones públicas en el mundo moderno, Madrid: PPC, 2000

Cortina, A., «Ciudadanía democrática. Ética, política y religión. XIX Conferencias Aranguren», Isegoría, 44, 2011, 13-55

Dawkins, R., The God Delusion, London: Bentam Press, 2006

Douglas, M., «Judgements on James Frazer», Daedalus, 107/ 4, 1978, 151-164

Elshtain, J. B., Public Man, Private Woman, Princeton: Princeton University Press, 1981

Flores d'Arcais, P., "Once tesis contra Habermas», Claves de Razón Práctica, 179, 2008, 56-60 
Habermas, J., Carta al Papa. Consideraciones sobre la fe, Barcelona: Paidós, 2009

- «La voz pública de la religión. Respuesta a las tesis de Flores d'Arcais», Claves de Razón práctica, 180, 2008, 4-6

- Entre el naturalismo y religión, Barcelona: Paidós, 2006

- «iIsrael o Atenas? A quién pertenece la razón anamnética. Sobre la unidad en la diversidad multicultural», Isegoría, 10, 1994, 107-116

Kymlicka, W., "Multiculturalism and Minority Rights: West and East», Journal on Etnopolitics and Minority Issues in Europe, 4, 2002, 1-26

Lafont, C., "Religion in the Public Sphere: Remarks on Habermas's Conception of Public Deliberation in Pos-Secular Societies», Constellations, 14/2, 2007, 239-259

Luckmann, T., La religión invisible, Salamanca: Sígueme, 1973

Luhmann, N., La religión de la sociedad, Madrid: Trotta, 2007

Puleo, A. (Ed.), Ecología y género en diálogo interdisciplinar, Madrid: Plaza y Valdés, 2015

Rawls, J., El liberalismo político, Barcelona: Crítica, 1996

Ungureanu, C., «Razón pública, religión y traducción: prospectivas y límites del postsecularismo de Habermas», Revista española de ciencia política, 32, 2013, 183-201

Weber, M., La ética protestante y el espíritu del capitalismo, Madrid: Alianza editorial, 2004. 



\section{RESEÑAS BIBLIOGRÁFICAS}


